Fecha de recepción: marzo 2017 Fecha de aceptación: octubre 2017 Versión final: marzo 2019

\section{Wright Mills y su crítica al diseño de segunda posguerra. Los aportes de la sociología al mundo del diseño}

Verónica Paiva * y Alejo García de la Cárcova ${ }^{\star *}$

Resumen: El artículo profundiza sobre dos textos elaborados por el sociólogo Charles Wright Mills en donde critica la posición que tomó el diseño industrial desde la crisis del '29 y en especial desde la Segunda Posguerra. El autor reprocha a los diseñadores industriales haber dejado su rol como parte del aparato cultural para ser miembro del aparato comercial, al prestar sus conocimientos sobre arte y diseño a la gran industria. Desde la crisis de sobreproducción del '29 el capitalismo se dinamizó a través del consumo masivo y la obsolescencia programada es decir, del desgaste de los objetos por cuestiones de prestigio o moda. En esa tarea el diseñador fue un engranaje indispensable al generar nuevas estéticas que promueven el cambio de moda o al vincular los objetos al status socioeconómico. Por esa razón Wright Mills invita a los diseñadores, arquitectos, paisajistas, planificadores urbanos, a volver a pensar su lugar social y promover políticas que contribuyan al bienestar humano.

Palabras clave: Diseño - Estética - Teoría Sociológica - Consumo Masivo - Obsolescencia Programada.

[Resúmenes en inglés y portugués en la página 117]

(*) Licenciada en Sociología y Doctora de la Universidad de Buenos Aires, Área Ciencias Sociales. Es docente e investigadora de la Facultad de Arquitectura, Diseño y Urbanismo de la Universidad de Buenos Aires e investiga en temas de hábitat y diseño. Dirige proyectos de investigación UBACyT desde el año 2003 y es Docente Investigadora categoría II del Programa de Incentivos Docentes del Ministerio de Educación de la Nación. Dicta clases de metodología en el Doctorado en Diseño de la UP.

${ }^{(*)}$ Diseñador Industrial (ORT). Carrera de Formación Docente (FADU/UBA). Docente FADU/UBA y ORT. Se desempeña en el área de Posgrados y Publicaciones Académicas de la Facultad de Diseño y Comunicación y forma parte del Equipo de Evaluación de los Proyectos de Graduación (Universidad de Palermo). 


\section{Introducción}

Este artículo se inscribe en una línea de investigación que estudia los aportes de la sociología a los estudios visuales ${ }^{1}$ y del diseño. Si bien se trata de un campo de reciente formación lo cierto es que la imagen ha sido terreno de investigación sociológica desde hace muchos años a través de autores como Howard Becker (1974), Ervin Goffman (1976), Pierre Bourdieu (1965) o Jean Baudrillard (1968), mientras que el rol del diseño en el consumo fue materia de reflexión desde las ciencias sociales, a través de autores como Lipovetsky (1990) en sus trabajos sobre el consumo en la posmodernidad.

A pesar de este recorrido, no existen demasiados estudios que se hayan detenido en la interrelación entre la sociología y la visualidad, y menos aún en el cruce entre la sociología y el diseño, por lo cual, este trabajo aborda un texto de Wright Mills referido a los diseñadores que es muy poco conocido dentro de los estudios sociológicos y del diseño.

Nuestro interés radica en realizar un recorrido histórico por el pensamiento de este autor y desde allí detenernos en los aportes de la sociología a los estudios visuales y/o del diseño $y$, al revés, sobre el aporte del diseño al pensamiento sociológico. En términos más amplios, reflexionaremos en las relaciones entre cultura y diseño.

\section{Charles Wright Mills. Biografía y textos clave}

Charles Wright Mills fue un sociólogo estadounidense nacido en 1916 y muerto en 1962. Para cualquiera que haya estudiado sociología es un referente indiscutido al definir "la imaginación sociológica" como la cualidad mental que permite cruzar "biografía e historia" y dar cuenta de la especificidad de la mirada sociológica que es aquella que puede explicar lo individual por lo social y lo social en lo individual.

Entre las obras fundamentales de Wright Mills se cuentan Los nuevos hombres del poder: los dirigentes laborales americanos (1948), Cuello blanco: las clases medias en Norteamérica (1951), La élite de poder (1957) La imaginación sociológica (1959) o Escucha, yanqui: la revolución en Cuba (1960).

El ambiente social, político e intelectual que rodeó a Mills fue la sociedad de consumo y la cultura de masas, el ascenso de la sociedad de la información, la Guerra Fría, la revolución cubana y las características de la élite de poder en Norteamérica. Intelectual y teóricamente se trató de un pensador independiente que si bien retomó la línea interpretativa de Marx y de Weber, la reformuló para poder interpretar los problemas de la etapa en la que vivió. Fue un crítico furioso de Talcott Parsons y "su gran teoría" y a nivel político reprobó tanto a Estados Unidos como a la Unión Soviética. Además del funcionalismo, el ambiente teórico con el que convivió fue el crecimiento de los estudios sobre mass media de Merton y Lazarsfeld, como así también los sondeos de opinión pública y de consumo masivo que proliferaron con el desarrollo de la técnica estadística a partir de los trabajos de Lazarsfeld. Entre todos sus estudios Wright Mills tiene algunos referidos a los diseñadores y su lugar en el aparato cultural de la época. Se trata de estudios poco conocidos en la teoría sociológica de los que daremos cuenta en los puntos siguientes. 


\section{Wright Mills y los diseñadores}

En 1958 y 1959 Wright Mills dio dos conferencias en Aspen y Toronto, donde se refiere a las particularidades del diseño y del diseñador en la sociedad estadounidense de esa época. Tal como comenta Javier Treviño (2014), Mills no sólo tenía una vocación especial y personal por el arte, sino que el mismo desarrollaba actividades de fotógrafo, constructor y artesano en su tiempo libre, razón por la cual, la temática del diseño no le era ajena.

Una de ellas fue en 1958 en la Eight International Design Conference, en la que presentó el trabajo "El hombre en el medio. El Diseñador" en donde señala el lugar complejo y contradictorio que ocupan los diseñadores en la sociedad de consumo. Su trabajo tiene tres objetivos: describir las características del aparato cultural, indicar el contexto económico en que trabaja el diseñador e incitarlo a reconsiderar los ideales con los que desarrolla su tarea. En cuanto al aparato cultural, se trata de las organizaciones y medios donde se realiza la labor artística, científica e intelectual, como así también los canales por los cuales esa labor llega al público masivo. El diseño y el arte son parte del aparato cultural, así como los museos, los medios masivos de comunicación y todas las instituciones por donde circulan los productos culturales. Tal como señala Mills, el mundo no se percibe de modo neutro, sino con un significado elaborado por otros, que se adquiere en el proceso de vivir. En ese mundo de significados, los objetos y las imágenes ocupan un lugar central, no son neutras, sino plenas de sentido.

Como manifiesta Mills, desde la crisis de sobreproducción de la década de 1929 el capitalismo se reactivó a partir de la implementación de tres tipos de obsolescencias de los objetos: el desgaste tecnológico debido al paso del tiempo, el recambio porque "debe desgastarse" y el recambio por prestigio, es decir, la aparición de una nueva moda que impulsa al consumidor a deshacerse del antiguo objeto, a pesar de que su funcionamiento esté intacto. Con voz crítica, Mills señala que en esta nueva tesitura de acelerar el desgaste por moda o prestigio, el diseñador dejó de trabajar en el aparato cultural para ser parte del aparato comercial y agregar valor estético superfluo a los objetos, convirtiéndose, en muchos casos, en mero auxiliar de los empresarios e industriales. Por esa razón, Mills exhorta a los diseñadores a volver a ser parte del aparato cultural y a los valores de la artesanía y el artesano, es decir, a la fabricación de objetos que se realizan por el sólo placer de hacerlos y sobre los cuales el artesano conoce todo el proceso, sin la enajenación de vender el arte a los intereses de la industria del momento. (Wright Mills, 2008)

Posteriormente, en la conferencia brindada en Toronto en 1959, Wright Mills se refirió a las ciudades y el modo de vida surgido en ellas después de la Segunda Guerra Mundial. Las ciudades son grandes monstruos que crecieron sin planificación con gente atrapada en su interior. Los suburbios no son mejores, con personas que repiten rutinas, trabajos y conductas no creativas sin cuestionarse si existe otro modo de vivir. Al decir de Mills, estas personas toman ese orden como natural y no poseen la imaginación sociológica que les permitiría analizar las fuerzas estructurales que condicionan su carácter, que se relacionan, sin duda, con el valor que han tomado los bienes raíces en la acumulación capitalista. En ese recorrido los diseñadores, los arquitectos, los planificadores urbanos, los paisajistas y los publicistas sometieron su arte al capital sin dar un debate sobre la política estética dirigida a las grandes áreas urbanas, en pos de mejorar la calidad de vida humana. 
Es que, como bien señala Javier Treviño (2014), en la época en que Wright Mills escribe sus escritos, se desarrollaron los primeros suburbios del tipo "Levittowns", es decir, vecindarios ubicados en las afueras de la ciudad, construidos con viviendas de tipología similar y habitadas por una clase media en ascenso, con rutinas de vida parecidas, gustos parejos, pasatiempos y conductas recreativas homogéneas, socialmente conformistas y políticamente indiferentes. Se trataba de la clase media surgida con el crecimiento de la sociedad de consumo y la expansión del american way of life. La sociología criticó este estilo de vida a través de autores como el propio Mills. Desde el urbanismo, este modo de vida fue abordado y criticado por Lewis Mumford en su libro La ciudad en la historia (1961) sobre el que Wright Mills escribió una reseña llamada The way to necrópolis (Treviño, 2014, pp. 350-351).

\section{La Sociedad de Consumo}

Se trata del tipo de sociedad que emerge luego de la Segunda Revolución Industrial, en la cual el consumo se convierte en el gran dinamizador de la industria y el articulador de las relaciones humanas.

En la primera etapa del capitalismo, la modalidad central se basaba en la producción consumo. Sin embargo, este modelo se agota rápidamente ya que la cantidad de productos que generaban las máquinas era muy superior a la que podía comprar y consumir la población. La primera gran crisis del capitalismo se produjo en 1873 a partir de una baja general de precios producida por la mejora en los transportes y la aparición de nuevos mercados en las colonias europeas. El capitalismo salió de esta crisis con medidas proteccionistas sobre los productos nacionales, la aparición de nuevos mercados y las nuevas técnicas y fuentes de energías de la Segunda Revolución Industrial.

La segunda gran crisis -la Gran Depresión del '29- fue generada, entre otras causas, por la sobreproducción de objetos a los que la gran mayoría de la población no podía acceder debido a sus bajos salarios.

Si bien la salida de esta crisis es muy conocida, vale la pena volver a reseñarla: políticas keynesianas, taylorismo, fordismo, obsolescencia programada y consumo de masas.

El New Deal (Nuevo Trato) firmado por Roosevelt en 1933 implicó la puesta en marcha de las políticas keynesianas orientadas a motorizar la economía a través del aumento de salarios, la intervención del estado en la obra pública, la dinamización de la industria, y el consumo de masas.

El método de trabajo en serie de Taylor (1900) se activó con el fordismo a través de la cadena de montaje y la estimulación del consumo. En definitiva, Ford fabricaba los autos que consumirían sus propios obreros (Carosio, 2008).

Este maridaje entre consumo, políticas keynesianas, intervención estatal y altos salarios continuó durante el período posterior a la Segunda Guerra Mundial, a través del esquema del Estado de Bienestar y las altas tasas de crecimiento económico sostenidas al ritmo de la industria automotriz, los bienes de consumo y el transporte.

Pero todo este mecanismo no hubiera podido funcionar sin otro aspecto muy ligado a la producción y el consumo masivos: la obsolescencia programada. ¿De qué se trata? De 
provocar la renovación constante de los objetos para generar nuevos consumos, motorizar la economía y conservar los empleos e industrias.

Este modo económico productivo basado en el consumo masivo modeló un estilo de vida conocido como The american way of life o modo de vida estadounidense. A grandes rasgos, se trata de un estilo de vida basado en el consumismo, la necesidad constante de adquirir bienes materiales, el requerimiento del automóvil particular, la necesidad de cambiar los electrodomésticos por un modelo más nuevo, la comida elaborada, la creencia en que los logros económicos personales se deben totalmente al éxito individual, sin mediación alguna de políticas públicas.

La sociología y la filosofía criticaron duramente este perfil de sujeto modelado por el consumo a través de autores como Marcuse, Baudrillard o el propio Wright Mills. Y el diseño, ¿en cuánto contribuyó a acelerar el consumismo?

\section{El Diseño y el consumo masivo}

Desde la década de 1920 la producción industrial de objetos de consumo masivo dominará el mercado y el paisaje internacional. Y el estilo predominante al cual acudirá como respuesta de la crisis de 1929, una y otra vez y más que indiscriminadamente, será el streamline o estilo aerodinámico, "que plantea la forma de 'lágrima' como la que más se adaptaba al concepto de velocidad" (Gay, 2007, p. 155). Según Aquiles Gay:

La aerodinámica se aplicó también a objetos que no tenían porqué ser tenidos en cuenta como dinámicos y se popularizó tanto (...) que ha llegado a ser considerada como sinónimo del diseño industrial estadounidense de los años $30 \mathrm{y}$ 40. Cuando no está vinculado a la función, es una variante del styling y se pretende simbolizar, dinamismo, modernidad, velocidad (...). (Gay, 2007, p. 155)

El styling será la denominación general que se le asignará -a partir de la década del 30-a aquellos productos que irán modificando su apariencia -al igual que el ritmo de las temporadas en la moda de indumentaria- para poder generar el deseo de compra; sin considerar, la mayoría de las veces: ni el aspecto funcional del objeto, ni su caducidad. A partir de la creación en 1928 de la Sección de Arte y Color -por la General Motors, y bajo la dirección de Harley Earl- se aplicará este proceso de maquillaje en la industria automotriz, como puntapié para al resto de la producción de productos en serie. En 1938, esta sección pasará a denominarse Styling Section (Heskett, 1980). La más de las veces, el styling se vincula con la simple modificación de la parte exterior de un producto -denominado carcasa-cuando esta oculta o contiene las piezas mecánicas, por seguridad e higiene. Algunos de los primeros estilistas responsables de esta operación superficial, según varios historiadores o teóricos del diseño (Dorfles, Lucie-Smith, Bürdek) -y en algunas oportunidades denominados como "pioneros del diseño industrial norteamericano"- fueron: Raymond Loewy, Norman Bel Geddes, Henry Dreyfuss, Egmont Arens y Walter Dorwin Teague, entre otros; que eran contratados como consultores en las industrias. En ocasiones $-\mathrm{y}$ fuera 
del sector automotriz- se considera a Loewy, como el primero en recibir un encargo para realizar el carcaseo de una duplicadora, para la empresa Gestetner.

El segundo término emparentado con otro concepto funcional a la industria será el denominado obsolescencia programada, es decir, el diseño de productos destinados a caer en desuso en breve tiempo. Una de las primeras menciones a la obsolescencia programada la realizó el inversor inmobiliario Bernard London en 1932, quien propuso el vencimiento forzoso de los productos en una fecha determinada por ley y la entrega al gobierno para su destrucción (Dannooritzer, 2010). De hecho, uno de los primeros exponentes de la obsolescencia deliberada fue la bombita eléctrica, diseñada originalmente para durar más de 100 años. En 1924 se creó Phoebus, un grupo integrado por diversas compañías eléctricas, para intercambiar patentes, controlar la producción y reorientar el consumo. Se trataba de que los consumidores compraran bombitas periódicamente por lo que en pocos años la duración de estas pasó de 2.500 horas a 1.500 horas. En 1942 se habilitó una denuncia del gobierno de EE.UU. contra General Electric y sus socios pero, pese a la sentencia, las bombitas siguieron funcionando con una media de 1.000 horas (Dannooritzer, 2010).

En la década de 1950 se activó la propuesta de obsolescencia programada bajo otro concepto: convencer a los consumidores de la necesidad de renovar sus objetos periódicamente, activar el deseo permanente hacia productos nuevos y conjugar consumo, deseo y felicidad.

En esta propuesta, el marketing y la publicidad tuvieron un rol fundamental. En cuanto al marketing, desde 1950 se convirtió en impulsor de la industria, mientras que como disciplina mejoró su cuerpo teórico y técnico. Peter Drucker (1909-2005), el padre del marketing, afirmaba que: "cualquier empresa tiene dos y sólo dos funciones básicas: marketing e innovación" (1954). En cuanto a la publicidad, también se afirma durante estos años y de a poco pasará de la divulgación de las bondades del objeto a la propaganda de una serie de virtudes simbólicas que se asocian al consumo de ese objeto. El desarrollo de una parte de los estudios sociológicos de esa época, tal como los de Lazarsfeld en materia de opinión pública y mass media, así como los avances en métodos estadísticos, se usaron en marketing y publicidad. Baudrillard fue un crítico feroz de este tipo de publicidad que provoca que cada objeto que consumimos venga acompañado de su "doble publicitario", es decir, de un manto protector que nos protege frente a los imponderables de la vida diaria e incluso frente a las imperfecciones de los propios productos. "A través de la publicidad, como antaño a través de las fiestas, la sociedad exhibe y consume su propia imagen" (Baudrillard, 196; Caro Almela, 2007).

Acerca de los aspectos que puede presentar la obsolescencia programada, Charlotte y Peter Fiell (2006) mencionan las tres esferas que Vance Packard -feroz opositor a este conceptoidentifica en su libro de 1960: The waste makers. Allí, describe la dimensión de la obsolescencia funcional, donde un nuevo producto se propone al mercado como superador del anterior, la obsolescencia de calidad, que se relaciona directamente con la durabilidad del producto y la esfera de la obsolescencia por el deseo de obtener un producto más nuevo, más bello o más promocionado. En esta última esfera se apoya todo el concepto del styling. En relación a estos conceptos de obsolescencia programada y styling, Mills crítica el rol del distribuidor que: 
(...) es crear un volumen de masas de ventas continuas. La producción continua y expansiva requiere de un consumo continuado y expansivo, de modo que el consumo debe ser apresurado por todas las técnicas y fraudes del mercado. Además, las mercancías deben desgastarse más rápidamente (...). Es entonces cuando el desgaste se planifica y el ciclo económico se acorta deliberadamente. (Mills, 1958, p. 7)

En este contexto, durante las dos décadas previas a la Segunda Guerra Mundial, se terminará de delinear en Estados Unidos el rol del diseñador industrial. Un profesional "funcional a la industria", la que requerirá de los más variados artilugios para reactivar el capitalismo. En palabras de Bürdek: "Los diseñadores creyeron que su tarea era hacer los productos irresistibles, esto es, intentaron proyectar los deseos y esperanzas subliminales del usuario en los objetos para estimular su compra”. (Bürdek, 2007, p. 111)

En esa tarea, el diseñador pasó del aparato cultural al comercial y se convirtió en una celebridad ante los medios de comunicación. Esto último, al punto tal del caso del consagrado Raymond Loewy, quien fuera el primer diseñador en llegar a la tapa de la prestigiosa revista Time, en Octubre de 1949.

Además las industrias tomarán provecho de esta situación haciendo uso del nombre y la firma del diseñador: “(...) de la misma forma en que los críticos e historiadores de la pintura y la escultura lo habían hecho durante siglos”. (Sparke, 2010, p. 190)

Tanto a partir del crack de 1929, como durante las primeras décadas de la segunda posguerra, la clase media consumió un vasto repertorio de productos de fabricación industrial. Pero más que simples productos, lo que adquirió es la fantasía de estabilidad y progreso; con la ilusión de ser parte del sueño americano: siendo él - como individuo-quien decidía qué comprar; más allá de toda invasión visual, perpetuada por los medios de comunicación. Fundamentalmente, en los medios gráficos, como revistas de moda, interiorismo y decoración; como en las publicidades: primero desde la gran pantalla en los cines: verdaderas catedrales del entretenimiento y la evasión cotidianas; y luego en las pantallas de menores dimensiones, de los primeros televisores: donde el capitalismo penetraba triunfante en los hogares norteamericanos.

Para ello, retomando los ideales racionalistas de la Bauhaus y el Movimiento Moderno, truncados por el advenimiento del Nazismo y la consecuente Segunda Guerra Mundial, surgirán en ambos lados del océano Atlántico las corrientes relacionadas con el Buen Diseño: el Good Design norteamericano y la Gute Form alemana. Estas corrientes también llegarán de primera mano a Latinoamérica, por vías directas de influencia a través del protagonismo del Grupo Austral argentino -con su vínculo directo europeo con el arquitecto Le Corbusier y los ideales del Movimiento Moderno; como así también de la mano de Tomás Maldonado y Gui Bonsiepe: ambos actores activos en la Escuela Superior de Diseño Alemana en ULM: en el caso del Buen Diseño. Consolidada especialmente en Argentina con la posterior creación del Centro de Investigaciones sobre Diseño Industrial en 1962; esta última otorgará, a partir de su primer concurso en 1964, los siguientes premios: "Sólido de Plata, Sólido de Cobre, Etiqueta de Buen Diseño" (Rey, 2009, p. 43). Esta etiqueta provenía de la similar utilizada en Estados Unidos -otorgadas en los concursos organizados por el Museum of Modern Art (MoMA) neoyorquino, como así también por 
las otorgadas por el Design Council inglés (Fiell). Todas estas vertientes del Buen Diseño podrían resumirse en los diez mandamientos desarrollados por Herbert Lindinger, a saber: elevada utilidad práctica, seguridad suficiente, larga vida y validez, adecuación ergonómica, independencia técnica y formal, relación con el entorno, no contaminante para el medio ambiente, visualización de su empleo, alto nivel de diseño, estímulo sensorial e intelectual (Bürdek, 2007).

Algunos ejemplos exitosos y paradigmáticos de esta última corriente mundial, podrían simplificarse en las figuras de: Charles y Ray Eames en los Estados Unidos, comercializando sus variados objetos en la firma Herman Miller; Dieter Rams en Alemania, diseñando la mayor parte de los productos en la empresa Braun; Robin y Lucienne Day en Inglaterra; Alvar Aalto que, en sociedad con su esposa Ainio y otros, funda la empresa de ventas y marketing Artek en Finlandia (Fiell, 2005). En Argentina, también son varias las empresas o locales de venta y diseñadores que abrazaran el Buen Diseño. Cabe resaltar la cuádruple labor de Alberto Churba: diseñador, promotor del diseño local, importador de diseño mayormente nórdico, italiano y norteamericano, y fundador del afamado local CH Centro de Arte y Diseño (Churba, 2008).

Si bien el Buen Diseño se contrapone, en muchos aspectos, con el styling, el streamline y su obsolescencia, será un nuevo estilo funcional al estilo de vida americano, como así también para su expansión mundial por vías de la institucionalización a través del aparato cultural y la promoción publicitaria en el aparato comercial.

\section{En síntesis}

Desde fines de la Segunda Guerra Mundial se afirma la producción en masa y la sociedad de consumo. El capitalismo se reactivó mediante una mezcla de fordismo y política económica keynesiana que otorgó a las clases populares salarios acordes a las necesidades de consumo que requería el propio capitalismo.

El diseño y los diseñadores no fueron ajenos a estas demandas del comercio y la industria, y mediante estilos como el streamline o el styling y posteriormente con el Good Design, provocaron la obsolescencia programada de los productos a través de alguna sus tres variantes por desgaste, moda o status socio económico.

En este contexto surge una clase media caracterizada por el consumismo, la apatía y el modo rutinario de vida cuyas características fueron analizadas por la sociología a través de autores como David Riesman en La muchedumbre solitaria (1950), Herbert Marcuse en El Hombre Unidimensional (1964) o Lewis Mumford en La ciudad en la historia (1961) en donde estudia el nuevo estilo de vida que se extendió en los suburbios estadounidenses de la época. Charles Wright Mills no fue ajeno a este ascenso del consumismo y en diversas conferencias criticó el rol que tomaron los diseñadores en esta etapa del capitalismo, como así también el papel de los arquitectos, los paisajistas, los publicistas y los planificadores urbanos que vendieron sus capacidades artísticas al aparato comercial, sin batallar por una política estética que mejore la calidad de vida en las ciudades.

Puede afirmarse que el diseño constituye una ventana que le permite a Mills analizar las nuevas subjetividades surgidas en la época y el papel de los objetos en esa construcción 
subjetiva. Concretamente, se trata de la nueva clase media protagonista del american way of life, caracterizado por el consumismo como estilo de vida, las conductas homogéneas, el carácter social y políticamente apático, la uniformidad en las formas de vivir y habitar el espacio, la recreación rutinaria y atada a las sugerencias de los medios de comunicación masiva, dentro de las cuales el diseño, los diseñadores y los profesionales de la ciudad, no han hecho más que reforzar ese carácter más que batallar para la generación de subjetividades más libres y creativas.

Contra esta enajenación del individuo y esta banalización del producto, Mills propone el regreso a los valores de la artesanía como “(...) común denominador del arte, la ciencia y el conocimiento y también la raíz misma del desarrollo humano (...). Porque el ideal humano más elevado es convertirse en un buen artesano" (Mills, 2008, p. 5). En esta frase retoma las ideas de William Morris quien -en su conferencia impartida en 1883- alerta: “(...) que nada que no cause placer tanto al productor como al usuario debe fabricarse y ese placer de fabricar ha de producir arte en manos del trabajador”. (Morris, 2005, p. 125) Tal como enseña en La imaginación sociológica (1959), examina el diseño y el rol de los profesionales como un emergente entre la biografía e historia, señalando la alienación que generan estas formas de producción estética y de labor profesional. Pero como buen intelectual que fue, no se queda en el análisis de época sino que reclama a los profesionales la producción de modos menos enajenados de relación entre arte y sociedad.

Por ello, puede decirse que los estudios sociológicos permiten reflexionar sobre el rol de la cultura de una época a través del análisis de los objetos producidos. Al revés, los objetos y su estética, en tanto productos culturales de un momento histórico, habilitan el estudio de los elementos estructurales (producción económica, actores intervinientes con mayor o menor poder) que condicionan su emergencia y sus modos particulares de manifestarse en cada época.

Además, si entendemos la cultura en su definición semiótica tal como la caracteriza García Canclini “(...) la cultura abarca el conjunto de procesos sociales de producción, circulación y consumo de la significación de la vida social” (2004, p. 35), queda claro que Mills realizó un gran aporte a la reflexión entre diseño y cultura al resaltar el valor de símbolo (ritos) y de signo (status socioeconómico) que produce el diseño y los diseñadores al elaborar objetos que permiten dinamizar el consumismo y el capitalismo.

Para cerrar cabe decir que si bien en América Latina Charles Wright Mills fue un autor muy apreciado por la izquierda latinoamericana y sus textos fueron de lectura obligatoria en los cursos de metodología y sociología que dictaba Gino Germani a fines de la década de 1950 (Germani, 2004), sus escritos sobre diseño y diseñadores nunca fueron difundidos.

\section{Notas}

1. Los estudios visuales conforman un campo de estudios que surgió durante la década de 1990 a partir del cruce de dos campos de estudio, la historia del arte y los estudios culturales (una manera de analizar los fenómenos sociales). En esta línea el concepto de historia es sustituido por el de cultura y el concepto de arte por el de "lo visual" (Krochmanly y Zarlenga, 2009). 


\section{Referencias Bibliográficas}

Baudrillard, J. (2014). El sistema de los objetos. México, D.F: Siglo veintiuno.

Becker, H. (1974). Photography and Sociology. Studies in the Anthropology of Visual Communications 1. 1974, 4-10.

Bourdieu, P. (1965). Un art moyen. Essai sur les usages sociaux de la photographie. Paris: Les Editions de Minuit.

Bürdek, B. (2007). Historia, teoría y práctica del diseño industrial. Barcelona: Gustavo Gili.

Caro Almela, A. (2007). Jean Baudrillard y la publicidad. Pensar la Publicidad, Vol I, (2), pp. 131-146.

Carosio, A. (2008). El género del consumo en la sociedad de consumo. La ventana, revista de estudios de género, Vol 3 (27). Recuperado de http://www.scielo.org.mx/scielo. php?script=sci_arttext\&pid=S1405-94362008000100006

Churba, A. (2008). Churba: 30 años de diseño. Buenos Aires: Infinito.

Dannoritzer, C. (2010). Comprar, tirar, comprar. [Película cinematográfica]. España. Radio Televisión Española (RTVE).

Dorfles, G. (1977). El diseño industrial y su estética. Barcelona: Labor.

Drucker, P. (1954). The Practice Of Management. EEUU: Harper y Brothers.

Fiell, C. y Fiell, P. (2005). Diseño Escandinavo. Madrid: Taschen. . (2006). Design Hanbook: Concepts, Materials, Styles. Madrid: Taschen.

García Canclini, N. (2004). Diferentes, desiguales y desconectados. Barcelona: GEDISA.

Gay, A. y Samar, L. (2007). El diseño industrial en la historia. Córdoba: Tec.

Germani, A. (2004). Gino Germani. Del antifascismo a la sociología. Buenos Aires: Taurus.

Goffman, E. (1976). Gender Advertisements. Studies in the Anthropology of Visual Communication, vol. 3 (2), pp 23-29.

Heskett, J. (1980). Industrial design. London: Thames and Hudson.

Krochmalny, S. y Zarlenga, M. (2009). Estudios Visuales y Cultura Visual. Un estado de la cuestión. V Jornadas de Jóvenes Investigadores del Instituto Fino Germani-Facultad de Ciencias Sociales, UBA Recuperado de: http://webiigg.sociales.uba.ar/iigg/jovenes_ investigadores/5jornadasjovenes/EJE4/Mesa\%202/Krochmalny\%20y\%20Zarlenga.pdf

Lipovetsky, G. (1990) El imperio de lo Efímero. Barcelona: Anagrama.

Lucie-Smith, E. (1983). A History of Industrial Design. Oxford: Phaidon.

Marcuse, H. (1964). El hombre unidimensional. Madrid: Ariel.

Mills, C. W. (2008). [1958] The man in the middle. The Designer. In J. H. Summers (Ed.), The politics of truth: Selectedwritings of C. Wright Mills. New York: Oxford University Press, pp. 173-183.

Mills, C. W. (1961) [1959]. La imaginación sociológica, México, Fondo de Cultura Económica. Morris, W. (2005). Cómo vivimos y cómo podríamos vivir. La Rioja: Pepitas de calabaza.

Mumford, L. (1961). La ciudad en la historia. Sus orígenes, transformaciones y perspectivas. New York: Harcourt, Brace \& World.

Rey, J. A. (2009). Historia del CIDI: Un impulso de diseño en la industria argentina. Ciudad de Buenos Aires: Red amigos CMD.

Riesman, D., Glazer, N. y Revel, D. (1950). The Lonely Crowd. A Study of the Changing American Character. New Haven: Yale University Press. 
Sparke, P. (2010). Diseño y cultura una introducción. Desde 1900 hasta la actualidad. Barcelona: Gustavo Gili.

Treviño, J. (2014). C. Wriht Mills as Designer: Personal Practice and Two Public Talks. The American Sociologist, Vol 45 (4), 335-360.

Abstract: The article elaborates on two texts written by sociologist C. Wright Mills where he criticizes the position taken by industrial designers since the 1929 crisis and especially since the Second World War. The author complains that the designer have left their role as part of the cultural apparatus to be a member of the commercial apparatus, in providing their knowledge of art and design to big industry. Since the ' 29 crisis of overproduction invigorated capitalism through massive consumption and planned obsolescence of objects for reasons of prestige or fashion. In this task the designer was indispensable to generate new aesthetic that promote change in fashion or by linking objects to socioeconomic status gear.

For that reason Wright Mills invites designers, architects, landscape architects, urban planners, to rethink their social responsibilities and promote policies that contribute to human welfare.

Key words: Design - Aesthetics - Sociological Theory - Mass Consumption - Planned Obsolescence.

Resumo: O artigo aprofunda sobre dois textos elaborados pelo sociólogo Charles Wright Mills onde critica a posição que tomou o design industrial desde a crise do '29 e especialmente desde a Segunda Guerra Mundial. O autor critica aos desenhadores industriais ter deixado seu papel como parte do aparelho cultural para ser membro do aparelho comercial, ao prestar seus conhecimentos sobre arte e design à grande indústria. Desde a crise de sobreprodução do '29 o capitalismo dinamizou-se através do consumo em massa e a obsolescência programada isto é, do desgaste dos objetos por questões de prestígio ou moda. Nessa tarefa o desenhador foi uma engrenagem indispensável ao gerar novas estéticas que promovem a mudança de moda ou ao vincular os objetos ao status socioeconômico. Por esa razón Wright Mills convida a los desenhadores, arquitetos, paisagistas, planejadores urbanos, a voltar a pensar seu lugar social e promover políticas que contribuam ao bem-estar humano.

Palavras chave: Design - Estética - Teoria Sociológica Consumo em massa - Obsolescência Programada. 